\title{
TRABALHO COM PROJETOS NA PRÁTICA PEDAGÓGICA DA EDUCAÇÃO FÍSICA
}

Denise Ivana de Paula Albuquerque

Universidade Estadual Paulista - UNESP, Faculdade de Ciências e Tecnologia, Presidente Prudente, SP. E-mail: denise@fct.unesp.br.

\section{RESUMO}

Este estudo é resultado do trabalho realizado na prática pedagógica da Educação Física Escolar. O objetivo foi apresentar a metodologia do Trabalho com Projetos como instrumento de intervenção nas aulas de Educação Física. O embasamento teórico utilizado neste estudo foi alicerçado nos princípios da pesquisa qualitativa. O projeto desenvolvido foi Caminhada do Bem, e envolveu diversos segmentos da escola, abordou temas como conhecimento do corpo e meio ambiente. Os resultados demonstraram que a metodologia proposta possibilitou uma aprendizagem significativa dos alunos demonstrando que a contemporaneidade exige do professor a adoção de metodologias e estratégias de ensino que promovam a construção de conhecimentos contextualizados.

Palavras-chave: Educação Física, Metodologia, Prática Pedagógica, Trabalho com Projetos.

\section{WORKING WITH PROJECTS IN THE PEDAGOGICAL PRACTICE OF PHYSICAL EDUCATION}

\begin{abstract}
This study is the result of work performed in the pedagogical practice of the school physical education. The goal was to present the methodology of working with projects as an instrument of intervention in the physical education classes. The theoretical basis used in this study was based on the principles of qualitative research. The project developed was walking Well, and involved various segments of school, addressed topics such as knowledge of the body and the environment. The results showed that the proposed methodology made possible a significant learning of students demonstrating its contemporary requires the teacher to adopt methodologies and teaching strategies that promote the construction of contextualized knowledge.
\end{abstract}

Keywords: Physical Education, Methodology, Pedagogical Practice, Working with Projects 


\section{INTRODUÇÃO}

O mundo e a sociedade estão em constante mudança, em termos materiais, em valores e princípios, nas representações simbólicas; esse fenômeno se dá em diferentes esferas, econômica, política, social e cultural. Essas várias dimensões cotejam com o movimento dialético das transformações educacionais. Nesse percurso, ao mesmo tempo em que emergem as críticas ao paradigma vigente, seja para concordar ou discordar do que está sendo posto por teorias ou concepções, também vão sendo elaborados novos referenciais, que consigam dar conta dos novos acontecimentos e processos em curso.

Nesse contexto, as questões que tratam do ensino da Educação Física escolar, partem do pressuposto de que a escola tem um papel fundamental: ela é o local ideal para se concentrar todos os trabalhos que englobem diferentes linguagens e a diversidade cultural, onde se deve valorizar e compartilhar as experiências vívidas e vivenciadas por alunos e professores, além de oferecer espaço para demonstração e discussão de experiências peculiares não inerentes ao âmbito escolar.

É na escola que devemos nos despir de todos os preconceitos e pré-conceitos, atuando como educadores e disseminadores de uma cultura multifacetada. Entre os princípios norteadores estabelecidos nas Diretrizes Curriculares Nacionais para o Ensino Fundamental (MEC,1998), a diversidade de manifestações culturais, bem como a autonomia, solidariedade e respeito ao bem comum são fundamentais na educação e associa-se aos objetivos da Educação Física escolar.

Nesta perspectiva considera-se essa disciplina essencial não apenas para compor a matriz curricular da educação básica, mas para contribuir significativamente na formação ética, moral e cultural dos alunos. Segundo Libâneo (1998), o mundo sofre intensas transformações que afetam todos os campos. Para acompanhar esses avanços do mundo globalizado, professores e alunos necessitam refletir sobre suas posturas e assumir novas atitudes que contemplam as novas exigências do contexto educacional. A universalização do conhecimento deve propiciar alternativas que permita ao indivíduo, exercer a cidadania e ter participação social efetiva, portanto é dever das instituições de ensino assumir este compromisso.

A organização de um trabalho dessa natureza tem a função de evidenciar quais são os objetos de ensino e aprendizagem que devem ser privilegiados, servindo como subsídio ao trabalho do professor, que deverá distribuir os conteúdos a serem trabalhados de maneira diversificada e adequada às possibilidades e necessidades de cada contexto. Assim, não se trata de uma estrutura estática ou inflexível, mas sim de uma forma de organizar o conjunto de conhecimentos abordados, segundo os diferentes enfoques metodológicos adotados pelo professor.

Uma metodologia, que vem sendo utilizada no contexto escolar, pelos professores de diferentes componentes curriculares, é a baseada no Trabalho com Projetos.

Um conceito que define bem o termo projeto significa projetar-se, dar forma a uma ideia, por meio de atitudes que desenvolvam as habilidades de cada um, de habilidades para poder caminhar. Assim, o projeto desenvolve atitudes que contribuem para que os alunos sejam motivados a avançar, a querer aprender sempre, compartilhando suas ideias, não se isolando, colaborando com pessoas e grupos na construção de uma sociedade mais justa. E Trabalho significa colocar-se à disposição para a implementação ou realização de uma ideia, no sentido de aprender fazendo, ou seja, o professor não oferece tudo 'pronto', mas estimula os alunos a pesquisarem para formalizarem o saber e o fazer, para compreender (SCHLÜNZEN \& SANTOS, 2008).

O Trabalho com Projetos, conforme está sinalizado nos Parâmetros Curriculares Nacionais, é uma das formas de sistematizar o trabalho didático, que pode integrar diferentes modos de organização curricular. Pode ser utilizado, por exemplo, em momentos específicos do 
desenvolvimento curricular de modo a envolver mais de um professor e uma turma, articular o trabalho de várias áreas, ou realizar-se no interior de uma única área.

Frente a essa proposta, evidencia-se a importância em torno de novas abordagens e práticas para a Educação Física. Assim, o objetivo deste estudo foi apresentar a metodologia do Trabalho com Projetos como instrumento de intervenção nas aulas de Educação Física.

\section{METODOLOGIA}

Esse estudo é fruto de estudos desenvolvidos no projeto do Núcleo de Ensino: Escola e Universidade dialogando sobre a práxis pedagógica na perspectiva do trabalho colaborativo, código de ética 122/2009. Foi desenvolvido em uma escola da rede pública com estudantes do 40 ano do Ensino Fundamental e embasado nos pressupostos da pesquisa qualitativa.

Os encaminhamentos para coleta de dados foram realizados através das intervenções nas aulas de Educação Física. Os dados foram tratados qualitativamente.

A análise qualitativa, segundo André (1983, p. 66) a análise qualitativa pretende "apreender o caráter multidimensional dos fenômenos em sua manifestação natural, bem como captar os diferentes significados de uma experiência vivida, auxiliando a compreensão do indivíduo no seu contexto".

\section{RESULTADOS}

Para que o processo de aprendizagem seja significativo, é fundamental que o professor considere na organização do trabalho educativo.

Na proposta de intervenção foram utilizados alguns elementos que subsidiaram as ações que tinham o objetivo de promover o desenvolvimento dos alunos em diversas dimensões, como: - a interação com alunos da mesma idade e de idades diferentes em situações diversas como fator de promoção da aprendizagem e do desenvolvimento e da capacidade de relacionar-se;

- os conhecimentos prévios de qualquer natureza, que as crianças já possuem sobre o assunto, já que elas aprendem por meio de uma construção interna ao relacionar suas ideias com as novas informações de que dispõem e com as interações que estabelece;

- a individualidade e a diversidade;

- o grau de desafio que as atividades apresentam e o fato de que devam ser significativas e apresentadas de maneira integrada para as crianças e o mais próximas, possíveis, das práticas sociais reais; a resolução de problemas como forma de aprendizagem.

O planejamento das atividades do Projeto implementado foi organizado juntamente com os alunos: primeiramente em uma aula foram apresentados vários conteúdos como: Esportes; Danças; Jogos Populares, Atividades lúdicas e recreativas. Todas as atividades deveriam ser relacionadas a diferentes temáticas: diversidade, meio ambiente, cultura, saúde.

Os alunos eram informados sobre o papel de cada um no projeto, e a importância do comprometimento nas ações. A professora da sala, também participou ativamente.

Após duas aulas para definição do projeto, o tema definido para o Projeto: "Caminhada do Bem". As atividades foram organizadas e sistematizadas para um semestre letivo.

A proposta teve a intenção de trabalhar com as dimensões conceituais, atitudinais e procedimentais. Conforme as orientações dos PCNs (1998), as atividades estavam articuladas e interrelacionadas com os conteúdos trabalhados em várias disciplinas.

A avaliação seguiu os pressupostos da avaliação formativa, nesse sentido, ocorreu em uma perspectiva processual de modo que os alunos tiveram oportunidade de se comprometerem com o processo de construção do conhecimento.

A seguir está apresentado um quadro, com as fases de desenvolvimento das atividades do projeto. 
Quadro 01. As atividades dos Projetos seguiram os encaminhamentos propostos por Portes (2010):

\begin{tabular}{|c|c|}
\hline Intenção & $\begin{array}{l}\text { Os objetivos educacionais foram definidos, foram consideradas as necessidades de } \\
\text { aprendizagem da turma, bem como a curiosidade e os interesses dos alunos para a } \\
\text { montagem do projeto. A partir daí, todas as atividades foram socializadas. Escolha } \\
\text { do tema. Identificação do nível de conhecimento dos alunos, conhecimentos } \\
\text { prévios, o levantamento de hipóteses, a listagem do que os alunos querem saber e } \\
\text { identificação de possíveis estratégias para o desenvolvimento do trabalho. }\end{array}$ \\
\hline Preparação & $\begin{array}{l}\text { Foram realizadas coleta e a seleção do material bibliográfico, através de revistas, } \\
\text { jornais, panfletos, livros didáticos, paradidáticos e literários, filmes, cd's, internet, } \\
\text { etc. Todo esse material estavam relacionados aos conhecimentos sobre os aspectos } \\
\text { da caminhada, os fatores sobre a anatomia do corpo; sobre o meio ambiente, entre } \\
\text { outros. } \\
\text { A sala foi dividida em os grupos de trabalho e suas respectivas tarefas foram } \\
\text { definidas em conjunto. } \\
\text { Foram organizados textos (redações) com o temas relacionados com o projeto, além } \\
\text { de atividades de pesquisa e estudos dos alunos. } \\
\text { E por fim foram enviados boletins informativos e convites para as famílias para } \\
\text { participar da atividade fim: a caminhada. }\end{array}$ \\
\hline Execução & $\begin{array}{l}\text { Após toda a preparação, fundamentada em estudos, debates que propiciar } \\
\text { conhecimentos acerca da temática, a caminhada foi agendada. } \\
\text { Houve uma mobilização de vários segmentos, a escola como um todo (professores, } \\
\text { servidores, alunos e família) se envolveram e participaram. }\end{array}$ \\
\hline Apreciação & $\begin{array}{l}\text { Na Avaliação do trabalho realizado em relação aos objetivos esperados, foi possível } \\
\text { observar conhecimentos sobre o corpo nos aspectos anatômicos e fisiológicos } \\
\text { envolvidos na caminhada. Conhecimentos sobre o meio ambiente. Assim foi possível } \\
\text { observar as informações novas compreendidas, as problemáticas esclarecidas e por } \\
\text { fim as aprendizagens construídas e o desenvolvimento evidenciado pelos alunos } \\
\text { durante a realização do projeto. }\end{array}$ \\
\hline
\end{tabular}

Os resultados apontaram uma ressignificação sobre questões relacionadas ao corpo e seus aspectos biológicos; da importância de cuidar do meio ambiente e demonstrando que a contemporaneidade exige do professor a adoção de metodologias e estratégias de ensino que promovam a construção de conhecimentos contextualizados.

\section{DISCUSSÃO}

Nessa perspectiva de trabalho, em que o aluno se transforma em um agente participativo da construção da sua aprendizagem, o papel do professor ganha novas dimensões. Ele deixa de ser um transmissor para ser um interventor, mediador que organiza atividades; mas é também, um facilitador, o que exige dele o conhecimento das condições sócio culturais, bem como das expectativas dos alunos em relação ao conteúdo proposto.

Como incentivador do desenvolvimento da aprendizagem, o professor estimula a interação e a cooperação entre os alunos.

Para Hernandez e Ventura (1996, pag. 61) a função dos projetos é favorecer a criação de estratégias de organização de conhecimentos escolares em relação ao "tratamento da Informação e a relação entre os diferentes conteúdos em torno de problemas e hipóteses que facilitem aos alunos a construção de seus conhecimentos, a transformação da informação procedente dos diferentes saberes disciplinares em conhecimento próprio". 
O saber produzido na vivência nas aulas de Educação Física, apresentaram uma unidade teórico-metodológica condizente com as concepções presentes no contexto cultural, nessa perspectiva o estudo que ora se apresenta propiciou uma reflexão sobre as diferentes possibilidades para a área e de como elas estão podem contribuir na construção de novos conhecimentos.

Professores e alunos compartilham os objetivos do trabalho e os conteúdos são organizados em torno de uma ou mais questões. Uma vez definido o aspecto específico de um tema, os alunos têm a possibilidade de usar o que já sabem sobre o assunto; buscar novas informações e utilizar os conhecimentos e os recursos oferecidos pelas diversas áreas para dar um sentido amplo à questão (BRASIL, 1998).

\section{CONCLUSÕES}

O que se pretendeu aqui foi destacar que, práticas efetivas e as propostas pedagógicas, na área da Educação Física, precisam de uma metodologia dinâmica, que tenha um aspecto de inovação, essas condicionantes vem ao encontro dos pressupostos do Trabalho com Projetos.

Almeida e Fonseca (2000) apontam que o Trabalho com Projetos, possibilita aprender fazendo, agindo, e que experimentando é o modo mais natural, intuitivo e fácil de construir o conhecimento. Isso é mais do que uma estratégia fundamental de aprendizagem: é um modo de ver o ser humano que aprende. Ele aprende pela experimentação ativa do mundo. Os alunos tem oportunidade de aprender fazendo, adotar atitudes diante das situações, estabelecer novas considerações e informações, com competências para a resolução dos problemas.

Daí a importância da Educação Física escolar desenvolver um trabalho representativo a partir de conteúdos que sejam significativos, nesse sentido, a proposta apresentada neste capítulo, é relevante na medida em que os projetos podem ser direcionados para metas objetivas, com a produção de algo que sirva como instrumento de intervenção nas situações reais.

\section{REFERÊNCIAS}

ALMEIDA, F. J.; FONSECA JÚNIOR, F. M. Projetos e ambientes inovadores. Brasília: Secretaria de Educação a Distância - Seed/ Proinfo - Ministério da Educação, 2000.

ANDRÉ, M. E. D. A. Texto, contexto e significado: algumas questões na análise de dados qualitativos. Cadernos de Pesquisa, (45): 66-71, 1983.

BRASIL. Ministério da Educação. Secretária de Educação Fundamental. Diretrizes Curriculares Nacionais para o Ensino Fundamental. Brasília, 1998.

BRASIL. Ministério da Educação. Secretária de Educação Fundamental. Parâmetros Curriculares Nacionais. Brasília. 1998.

HERNÁNDEZ, F. VENTURA, M. A organização do currículo por projetos de trabalho: o Conhecimento é um Caleidoscópio. Artes Médicas, Porto Alegre, 1996.

LIBÂNEO, J. C. Adeus Professor, Adeus Professora? Novas exigências educacionais e profissão docente. São Paulo: Cortez, 1998.

PORTES, K. A. C. A organização do Currículo por Projetos de Trabalho. Revista Virtú de Ciências Humanas, Anais do III Simpósio de Formação de Professores de Juiz de Fora. Jiz de Fora, 2005. 
PRADO, M. E. B. B. Pedagogia de Projetos. In: Formação de Gestores Escolares para o uso de Tecnologias de Informação e Comunicação. Caderno Gestão Escolar e Tecnologias, 2005.

SCHLÜNZEN E. T. M. SANTOS D. A. N. Os projetos de trabalho e as Tecnologias de Informação e Comunicação - TIC potencializando a aprendizagem de pessoas "especiais. VII Congresso Iberoamericano de Informática Educativa, 2008. 